\title{
Mathematical Literacy Problem and Use of Intuition
}

\author{
Faiz Latif Usman, Budiyono, Diari Indriati \\ Department of Mathematics Education, Universitas Sebelas Maret Surakarta \\ faizlatifusman@student.uns.ac.id, budiyono53@yahoo.com, diari_indri@yahoo.com
}

\begin{abstract}
The digitalization of 21st-century in the society is focusing mathematical competence on computer performance where real-life problems are modeled into the language of mathematics. Mathematical literacy helps individuals to recognise the role of mathematics playing in the world and helping them to make the kinds of well judgements and decisions. Intuition is always based on particular schematic structure and spontaneous notion is a fact behind the schematic. If student are solving the problem, they use schematic structure. This research used the qualitative method with case study strategy. This study aims to describe intuition on mathematical literacy issues of the student from private high vocational school. This research use test method similar problems mathematical literacy in PISA and in-depth interviews. The subject of this study was a student who has first rank in the class. Based on the result of the research, the use of intuition to solve mathematical literacy problem is affirmatory intuition and anticapatory intuition.
\end{abstract} Literacy

Keywords- Decision Making; Intuition; Mathematical

\section{INTRODUCTION}

The development of information in the 21 st-century requires us to have the ability of reading, interpreting, and analyzing the unknown information of its true value. Misinformation affects our understanding and beliefs about an issue to be incorrect information. The recent phenomenon of misinformation is a topic that is often experienced by most of Indonesian people and even the world. One of them is hoax information, the spread of hoax information has long been happening in Indonesia, but the easier access to get information causes the spread of hoax information easily accessible to the public, especially social media internet users. According to Irwansyah who is an information expert from the Universitas Indonesia, the phenomenon of hoax information occurs because the ability of the Indonesian people to filter information from various media is not good [1]. Internet users in Indonesia reach 143.26 million people in 2017 and teenagers aged 13-18 years including senior high school students or vocational high school students occupy the third position with a portion of $16.68 \%$ [2]. Anyone can become a victim of hoax information including students when they access information using the internet [3]. If false information accessed by student, it will undoubtedly jeopardize the student' understanding and belief, so student need to have the ability to filter the information. This ability allows us to gather and organize important information to be used in various ways. This indicates the importance of literacy ability [4-6].

UNESCO, an organization engaged in the field of education explained that literacy is a major part of all basic education in which not only exist in classroom learning, but also play a very important role in the life of society [7]. The digitalization of 21 st-century in the society is focusing mathematical competence on computer performance where real-life problems are modeled into the language of mathematics. Directly, the purpose of mathematical learning is modeling and application to everyday life [8]. The mathematical problems in everyday life that are meant here are the same as the problems of mathematical literacy given by PISA [9]. Mathematical literacy in PISA is contained three processes such as formulate, employ and interpret mathematics in a variety of contexts. The three processes will make student as active problem solver will engage. Active problem solver will explore a problem with using a wide range of strategies to solve problem, as well as developing the processes of analyzing, reasoning, generalizing and abstracting [10]. Thus, mathematical literacy includes reasoning mathematically and using mathematical concepts, procedures, facts and tools to describe, explain and predict phenomena [11]. Mathematical literacy helps individuals to recognize the role of mathematics playing in the world and helping them to make the kinds of well judgements and decisions.

We use the combination of left and right brains when we solve problems $[12,13]$. Right side has a role for processing data thoroughly and left side is used to measure the logic in solving the problems. Intuition is always based on particular schematic structure and spontaneous notion is a fact behind the schematic [14]. Scheme is always an organized system of sequential interpretations and procedures jointly expressing a certain level of mental maturation and a sufficient amount of experience [14]. When student solve the problem, they use schematic structure. Student who are challenged with openended problems support the use of intuition in justifying reasons to determine the result or make a decision or correct answer [15]. These open-ended problems adapted from PISA. We need to know that intuition in mathematics is used as a thought bridge between abstract mathematics concept with the real world [16]. Therefore, intuition will rise up when student 
are solving problems especially the one related mathematics literation in PISA.

Intuition is a thinking activity that works as a bottle opener, someone's inspiration in directing the choice of constructive steps and find the solution from the current problems or probably a predictive and direct one $[14,16]$. Intuition is also formed based on experiences or current knowledge, but it's not only earned from a routine or common experience. It means the experience growth earned as a result of reflection thinking [17]. When student indirectly do reflection thinking, they evaluate mathematical assumption using reasoning intuition. The kind of intuition used based on its correlation between intuition and solution are (a) affirmatory intuition is one affirms or makes a claim, (b) conjectural intuitions is one in which an assumption about future events is expressed, (c) conclusive intuitions summarize in a global, structured vision the solution to a problem that previously been elaborated, and anticipatory intuitions are the cognition that implicitly emerges during an attempt at problem solving, immediately after serious search for a problemsolving strategy $[16,18]$.

Intuition in this research is not pure intuition, because it is not just random guessing. The guess is caused by information that is entered and manipulated or formed in mental or cognitive processes. This information is known as scheme which is collection of knowledge from individual long-term memory and used when dealing with new problems [19], especially mathematical literacy problems. Based on these, intuition and mathematical literacy is very important to solve problem in real life. So, this study to find out how the intuition a student from private high vocational school related to mathematical literacy problems.

\section{METHOD}

This research used qualitative method with descriptive research type and case study strategy. The sample used in this study was a student in class $\mathrm{X}$ of private high vocational school and has first rank in the class. This sample was chosen because based on observations in the field and recommendation from the teachers in the class, the student has better ability to understand the problem and strong will in facing new problems compared to other students in the same school. Then to make sure the validity of data, this study used the methodological triangulation. Researcher took a sample question from PISA 2009 about Water Tanks [20]. Results of data based on the work of mathematical literacy problems derived from the question of PISA. The student was asked to estimate, globally and justify their answers of the mathematical literacy problem. Data were gathered after the subjects answered in writing, in-depth interviews and asked to explain their solutions. In case of difficulty, the interviewer also acted as a prompter

\section{RESULTS AND DISCUSSION}

A. Theme: Water Tank

A water tank has shape and dimensions as shown in Figure 1.

At the beginning the tank is empty. Then it is filled with water at the rate of one litre per second.

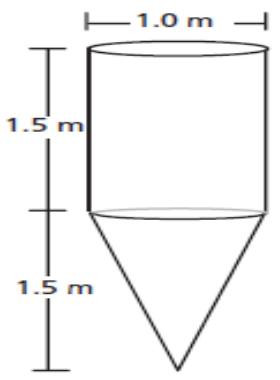

Figure 1: Water tank

1. Which of the following graphs in Figure 2 shows how the height of the water surface changes over time?

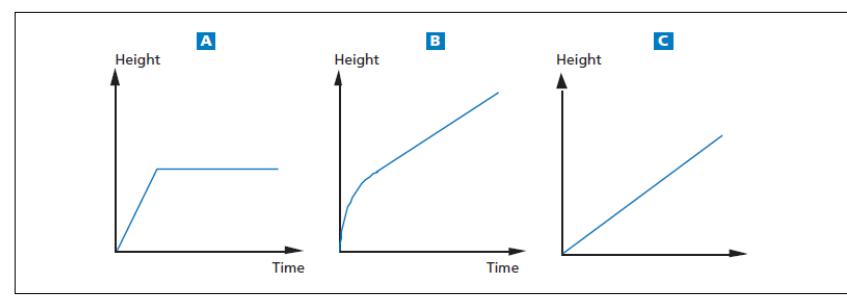

Figure 2: Graphs in water tank

$\mathrm{S}$ was still confused with the problem associated with the graph. When subject $\mathrm{S}$ understanding problem 3.1.1, he performed a series of thought processes. $\mathrm{S}$ was still trying to understand the points that are known in the matter. $\mathrm{S}$ observed the graphic sequence in Figure 2 and found a thing that blocked his mind. That was the difference of curve lines in graphs. $\mathrm{S}$ found from his observation, there was a change in the line and a curve which at a certain point of the line turned. Reaction of S occurs based on schema of the curve line. This schema called as Schema-1.

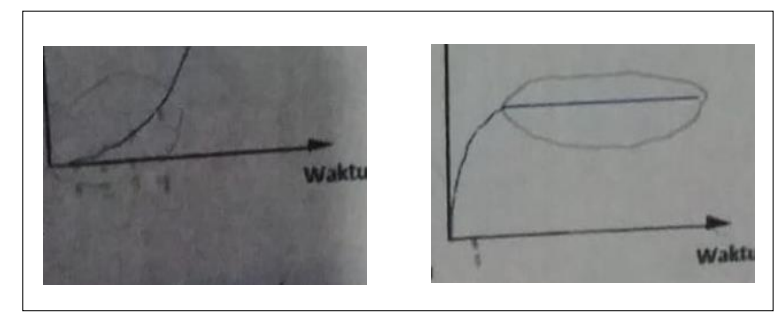

Figure 3: Schema-1 found by students'

In Schema-1, student needed to take a long time to understand the graphs. Student have experienced a deadlock to formulate information into language of mathematics (graphs). The student found something in his mind that was the difference shape in each curve and made a mark at the curves. Unconsciously the student used his intuition to understand the 
unclear matter with making a mark at the curve of graph D and E. The student thought, there was an important information can be obtained from those parts. When student was first times to guess the matter, the student was focus to the whole of the lines on the curve. Although the student still did not understand about the relationship between water height and time. This intuition is classfied as affirmatory intuition. Affirmatory intuition because student makes a claim that schema-1 is based on schema the difference of curved lines.

Subject $S$ was assisted by researcher to stimulate his thinking. $\mathrm{S}$ was asked by the researcher to understand the Figure 1 and describe the situation when the water tank was filled by water. Then $\mathrm{S}$ was asked again about the difference in water level before and after. Suddenly $S$ thought to select a graphic $\mathrm{C}$ because the curve continuously rises up. $\mathrm{S}$ thought that if the time is getting longer so the water is getting higher. $\mathrm{S}$ began to understand the usage of the graph shown in figure 2. While still incorrect, the reaction of $S$ occured based on the Schema of time-relation with the water level. This schema called as Schema-2. In schema-2, S still did not pay attention to the construction of shape on water tanks.

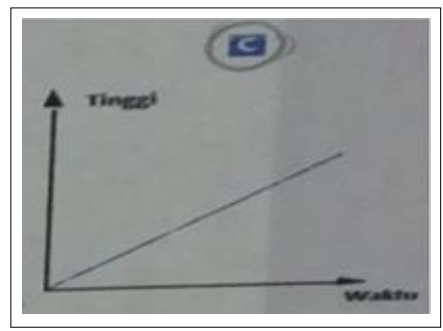

Figure 4: Schema-2 found by students'

In Schema-2, the student's knowledge began to increase and imagined the situation of the water tank slowly filled with at the rate 1 liter per second. Student thought that if time keep increasing then the water level also increases. Student felt that answer $\mathrm{C}$ is the correct solution. In planning the solution alike that thing, student use intuition to try to imagine their graphical representation into the water tank. This intuition is classified as Anticipatory intuition. Anticipatory intuition appears as a discovery, a solution to a problem and the sudden result of previous solving endeavor.

Researcher asked about S's belief in the choice of the graph C. S was looked silent and re-understand the given problem. The researcher asked $S$ opinions about graph $B$ and D. S was looked silent and S glanced at graph B. S saw a picture of a water tank. He spoke softly that the water tank was a building made up by cones and tubes. At first glance he looked at the Schema-1 (marked on the graph E). S became a doubt about his choice, he thought that the water of conereversed was progressively widened. Than $\mathrm{S}$ denoted the value of $\mathrm{x}$ and $\mathrm{y}$. The equations on graph $\mathrm{B}$ and $\mathrm{D}$ were substituted by the value of $\mathrm{x}$ with 1 and 2 , then value of $\mathrm{y}$ with 1 and 2 (Figure 5 and 6).

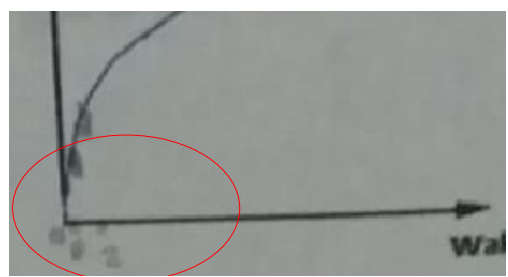

Figure 5: Value of $x$ and $y$ at graph B

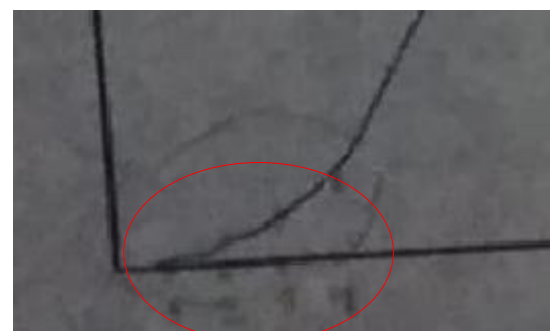

Figure 6: Value of $x$ and $y$ at graph D

After observing both of them, S supposed that graph B was the answer to question in 3.1.1. S was still confused when comparing between graph $\mathrm{B}$ and graph $\mathrm{D}$, he found out that both graphs equally have a rising curve. S's feelings or beliefs still dominat to graph B rather than graph D. S was asked by researcher to see the water tank again. Finally, $S$ was still convinced to choose the graph B although he was still unable to find the correct reason for choosing the graph B rather than the graph E. Accordingly, the schema used by $\mathrm{S}$ was a schema of an inverted cone with graphs B and D. This schema called Schema-3.

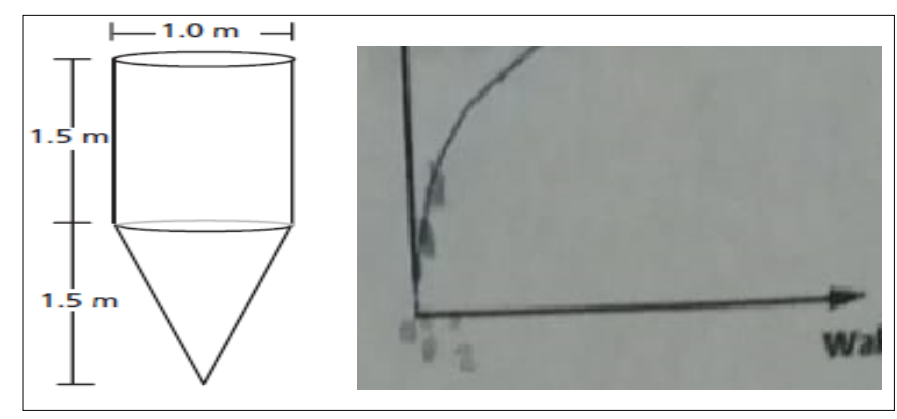

Figure 7. Schema-3 found by students'

In Schema-3, Student who had previously believed that graph c was the right solution but now became uncertain when comparing it with graph B and D. The student was silent and thought of Schema-1 where the graph curve A, B, D, and E at point certain will be turned. Student in Schema-2 already know that the more time it takes than the more height of the water will be increase. Graph of B, C and D are proved on the schema 2 and will become the once of right solution. Then the student realized that the water tank was formed from the reversed cones and the tubes, so that the length of the water was filled up in reversed cone and the tubes had time differences (seen on B and D charts).

The thing confused the student is how to explain the difference in graphs B and D. Student tried to create a value of 
$\mathrm{x}$ and $\mathrm{y}$ (Figure 5 and Figure 6). Student are still confused about the solution between the graph $\mathrm{B}$ or $\mathrm{D}$, but student' feelings is more dominant to the graph $\mathrm{B}$. The intuition used in the schema-3 is classified as anticipatory intuition. Classified the anticipatory intuition because the student tries to create the symbolization (the value of $x$ and $y$ ) and analyzes the answers from Schema-1 and Schema-2 to prove that the graph $\mathrm{C}$ is incorrect.

\section{CONCLUSION}

Based on the objectives and data analysis that has been done by the researcher can be concluded that in Schema-1 until to Schema-3, the use of intuition to solve mathematical literacy problem is affirmatory intuition and anticipatory intuition. Affirmatory intuition, student makes a claim that schema-1 is based on schema the difference of curved lines. Anticipatory intuition appears as a discovery, a solution to a problem and the sudden result of previous solving endeavor such as: (a) student use intuition to try to imagine their graphical representation into the water tank. The reaction of student is be equal to check the graph $\mathrm{C}$ into situation which the water tank is filled up with water, (b) student tries to create the symbolization (the value of $x$ and $y$ ) and analyzes the answers from Schema-1 and Schema-2 to prove that the graph $\mathrm{C}$ is incorrect.

In these schema show that intuition formed based on growth experiences earned as a result of reflection thinking. Intuition will rise up when student are solving problem of mathematics literation in PISA. So that, intuitions may be thought of as being based on some structuring rules expressing both levels of maturation and levels of training. This is an important task of the learning process one has to identify the structuring schemata and the specific ones which underlie the respective intuition.

\section{REFERENCES}

[1] Mizmir, Indonesia dan Hoax yang Menggurita, Depok: UI Lib. Berkala, 2017, p. 10.

[2] APCII, Infografis Penetrasi \& Perilaku Pengguna Internet Indonesia 2017, Jakarta: Tekno Preuner Indonesia, 2017.
[3] S. Respati, Mengapa Banyak Orang Mudah Percaya Berita "Hoax"?, Jakarta: Kompas, 2017.

[4] A. R. Pratama, D. R. S. Saputro, and Riyadi, "Problem solving of student with visual impairment related to mathematical literacy problem", Journal of Physics: Conference Series, 2017.

[5] D. Nur'aini, S. B. Rahardjo, and V. H. E. Susanti, "Student's profile about science literacy in Surakarta", Journal of Physics: Conference Series, 2018.

[6] D. Tokada, T. Herman, and Suhendra, "Discovery learning and mathematical literacy Ability", Journal of Physics: Conference Series, 2017.

[7] G. A. S. Moretti, and T. Frandell, "Literacy from a Right to Education Perspective", Report of the Director General of UNESCO to the United Nations General Assembly 68th Session, 2013.

[8] K. Gravemeijer, M. Stephan, C. Julie, "What mathematics education may prepare student for the society of the future?" Int. J. of Sci. and Math. Educ., vol. 15, no. 1, p.105, 2017.

[9] K. Stakey, "The PISA View of mathematical literacy in Indonesia", Journal on Mathematics Education (IndoMS-JME), vol. 2, pp. 95-126, 2011.

[10] A. Evans, A. A. Emmanuel, and O. D. William, "Problem solving framework for mathematics disciple", Asian Research Journal of Mathematics, vol. 4, no. 4, pp. 1-11, 2017.

[11] OECD, PISA 2015 Assessment and Analytical Framework: Mathematics, Reading, Science, Problem Solving and Financial Literacy, Paris: OECD Publishing, 2015.

[12] D. G. Myers, Intuisi Fungsi Insting dan Naluri untuk Meraih Kesuksesan, Yogyakarta: QALAM, 2004, pp. 29-34.

[13] M. Arsalidou, M. Pawliw-Levac, M. Sadeghi, and J. Pascual-Leone, "Brain areas associated with numbers and calculations in children: meta anlyses of fMRI studies", Development cognitive Neuroscience, pp. 1$12,2017$.

[14] E. Fischbein and A. Grossman, "Scemata and Intuition in Combinatorial Reasoning", Educational Studies in Mathematics, vol. 34, no. 1, pp. 2747, 1997.

[15] R. Bourn and S. C. Baxter, "Developing mathematical intuition by building estimation skill Atlanta: 120th ASEE Annual Conference \& Exposition", 2013.

[16] E. Fischbein, Intuition in science and mathematics: An educational approach, Newyork: Kluwer Academic Publishers, 2002.

[17] J. M. C. Nelissen, "Intuition and problem solving Curriculum and Teaching", vol. 28, no. 2, pp. 27- 44, 2013.

[18] C. H. Huang, "Mathematical problem solving and use of intuition and visualization by enginering student", American Journal of Educational Research, vol. 3, no. 12, pp. 1484-88, 2013.

[19] B. Panjaitan, "Proses kognitif siswa dalam pemecahan masalah matematika”, Jurnal Ilmu Pendidikan, vol. 19, no. 1, pp. 17-25, 2013.

[20] OECD, Take the Test Sample Question from OECD's PISA Assessements, Paris: OECD Publishing, 2009, p. 135. 